\title{
Employing Interface Compensators to Enhance the Power Quality In Hybrid AC/DC Microgrids
}

\author{
Saeed Daneshvar Dehnavi ${ }^{*}, 1$ - Mahdi Shahparasti 2 - Mohsen Simab ${ }^{1}$ - Seyed Mohammad Bagher \\ Mortazavi $^{1}$ \\ ${ }^{1}$ Department of Electrical Engineering Marvdasht Branch, Islamic Azad University, Marvdasht, \\ Iran \\ ${ }^{2}$ Department of Electrical Engineering, Tehran East Branch, Islamic Azad University, Tehran, Iran \\ *Corresponding author: Email: Sdaneshvard@gmail.com
}

\begin{abstract}
After the introduction of distributed generators, regarding the challenges these networks face, employing AC/DC Hybrid microgrids would be an undeniable issue due to its many advantages and it will certainly find a significant position. Thus, discussing the power quality in this type of microgrids and clean power for feeding the load via this microgrid is a drastic challenge. This paper proposing a hybrid microgrid with 2 interface converters, one placed in series and the other placed in parallel, tries to accomplish these control objectives in an AC microgrid in order to improve power quality: input sine current with $\operatorname{Cos} \phi=1$ and output sine voltage with normal value when source voltage is abnormal and non-sinusoidal, besides, non-linear loads' presence. Simulation results verify the favorable performance of converters and effective functionality of control systems.
\end{abstract}

Keywords - Hybrid microgrid, Power Quality, non-linear loads, series converter, parallel converter 


\section{Introduction}

Increasing cost of prevalent energy 【 resources, environmental limitations and technical issues has given rise to a growing trend for energy extraction from distributed generation resources, especially renewable resources. It is anticipated that by 2050, about $50 \%$ of total energy consumption would be provided by renewable resources [1], [2]. Low range of power generation in DGs, their high initial investment cost, lacking the ability to response quickly to load variations in many types of DGs, lacking the ability to be programmed and extensive changes in power generation in some of them, have introduced the issue of developing microgrids [3]. One of the most important issues regarding microgrids is the common bus which DGs and loads are connected to. This common bus can be AC or DC or a combination of both [4], [5]. Two conventional structures as AC microgrid and DC microgrid can be defined. Depending on the application, any of these structures can be a suitable option for developing the microgrid [6], [7]. Recently, a new structure, known as AC/DC hybrid microgrid has been proposed to reduce the system's construction costs and exploit the advantages of both microgrids [8]. It is proved that AC-DC hybrid microgrids, employing two separate AC and DC buses would be the best structure in terms of performance and costs. AC and DC buses are connected to each other via an inverter [8]. Voltage of the DC bus is the effective factor for choosing the interface inverter's structure in this type of microgrid [9]. In all of the above structures, there is one inverter in the system, which injects power to the grid when it is connected to the grid, and feeds the local load when separate. When it is connected to the grid, injected current's quality, active and reactive power exchanged with the grid and load's voltage are to be taken into account. Several standards have already been demonstrated for defining the injected current's criteria regarding the power grid's conditions and quality of the load's voltage [10]. Harmonic spectrum is the most important characteristic of the injected current UII. According to the standards
IEEE1547, IEC127, total harmonic distortion (THD) in injected currents UII should always be less than $5 \%$ and its imbalance should not be more than $1 \%$ [11]. In addition, concerning the effect of voltage imbalance on the system and equipments, International Electronics Commission (IEC) suggests the voltage imbalance not to be more than $2 \%$ [12]. Series active filter is employed to compensate the following effects: voltage drops, surplus voltage, interruptions and imbalance [13], [14]. Also, there are some tasks in which, voltage imbalance is compensated by parallel compensator. In these tasks, where the voltage imbalance is caused by unbalanced loads, compensation is done via balanced line currents. But when the load imbalance is very high, current injected by active filter might be very high and exceed filter's tolerance [15], [16]. A power quality compensator to be employed in microgrids is considered in [17]. Both microgrid's power quality and quality of the current between microgrid and the general network are considered, but its drawback is that it has not compensated the nonlinear loads. In another study, a DVR which is added by a UPQC structure is proposed to improve the grid's performance by regenerated control, but complexity of the control system and its high cost are the shortcomings [18]. A converter structure with 3-phase structure for a microgrid with unbalanced non-linear loads is proposed. This structure is suitable for a high power grid. But the voltage disturbance and SAG voltage on the point of common coupling (PCC) is not considered [19]. A control strategy based on the static reference framework is proposed to compensate the voltage disturbances, sensitive and nonlinear loads' effect and interruptions in a UPS, where generating an unfit voltage reference is their drawback. In another work, a power sharing unit is proposed to achieve power management strategy in a hybrid microgrid UPS structure [20]. In [21], a power sharing unit (PSU) is proposed to achieve power management strategy in a hybrid microgrid structure.

According to what has been explained, a hybrid microgrid structure in which instead of one converter, two converters are used as series and parallel interface compensator to 
compensate voltage disturbances and non-linear loads' effects on grid's current, such that series compensator resolves voltage issues by injecting voltage, and parallel compensator resolves nonlinear loads' effects. Performance of this grid is evaluated by simulations in SIMULINK.

\section{Proposed topology}

Power circuit of the proposed parallel-series compensator topology is shown in Fig. 1. Series converter and parallel converter of the AC-DC converters are reversible SPWM which are connected to the DC bus of the microgrid. Breaker is used to provide a quick dissociation between the microgrid and the power grid, in case of sudden interruptions in the input power of grid.

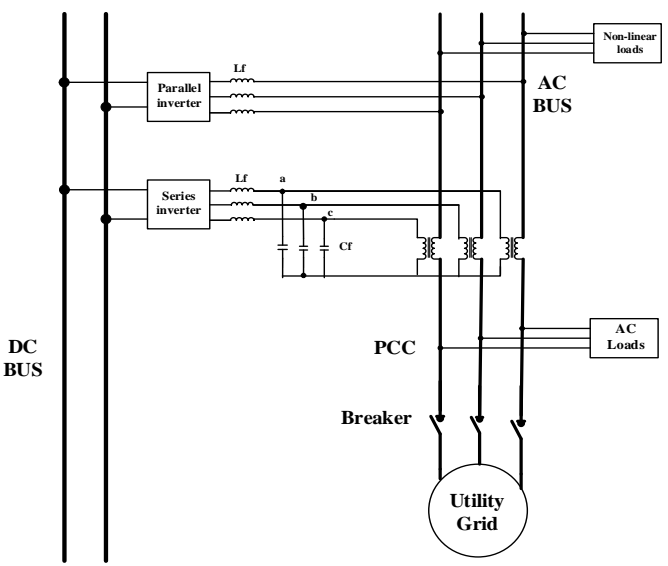

Fig.1: The proposed grid

In this grid, series converter's task is to balance and resolve voltage disturbances while parallel converter is used to resolve current disturbances. Fig. 2 shows the equivalent circuit of the interface converters connected between 2 microgrids. Where $V_{s}$ is the AC microgrid's voltage, $\mathrm{V}_{\text {sr }}$ is the compensation voltage of the series compensator, $\mathrm{V}_{1}$ is the load's voltage and Ish is the compensation current of the parallel compensator [22].

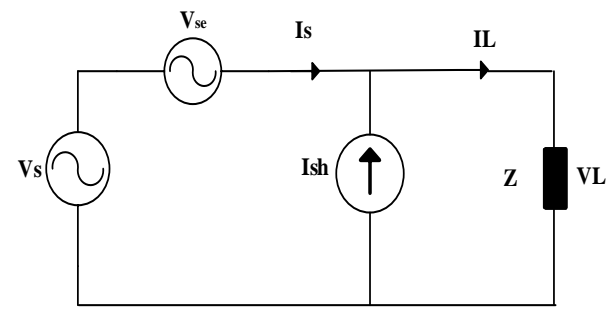

Fig.2: Equivalent Circuit of the Grid

Due to voltage distortion, system might include negative components and harmonic. In general, load's voltage would be as follows:
$\mathrm{V}_{\mathrm{s}}+\mathrm{V}_{\mathrm{se}}=\mathrm{V}_{1}$

To achieve a sinusoidal balance in load's voltage with the rectified value $V$, output voltage of the series converter should be like below:

$V_{s r}=\left(V-V_{1 p}\right) \sin \left(\omega t+\theta_{1 p}\right)-V_{1 n}(t)-\sum_{k=2}^{\infty} V_{k}(t)$

Where:

$V_{1 p}$ is the base frequency of the positive sequence voltage domain

$\theta_{1 \mathrm{p}}$ is the positive sequence for base phase of voltage

$\mathrm{V}_{\mathrm{ln}}$ is the negative sequence component

Parallel compensator works like a controlled current source and its output components should include harmonic, reactive component and elements of the negative component to compensate these values in loads' current.

When the output current of the parallel converter, Ish is equal to the load's current or a fragment of it, as shown in the equations below:

$i_{l}=I_{1 p} \cos \left(\omega t+\theta_{1 p}\right) \sin \varphi_{1 p}+V_{1 n}+\sum_{k=2}^{\infty} i_{l k}$

Where:

$\varphi_{1 p}=\varphi_{1 p}-\theta_{1 p}$

$\Phi_{1 \mathrm{p}}$ is the initial phase of current for positive component

As it can be seen from the above equations, harmonic, reactive and negative sequence currents do not flow from the power source. Therefore, source current's terminal is sinusoidal, without harmony and in-phase with the load's terminal voltage.

$I_{s}=I_{l}-I_{s h}=I_{1 p} \sin \left(\omega t-\theta_{1 p}\right) \cos \varphi_{1 p}$

\section{Power quality compensator \\ 3.1 Series Compensator}

The proposed series inverter's coupling circuit in microgrid is shown in Fig.1. Series inverter is used to keep the voltage's balance $(\mathrm{V}$ load a, V load b, V load c) and control [23]. The respective control system is shown in Fig. 3.

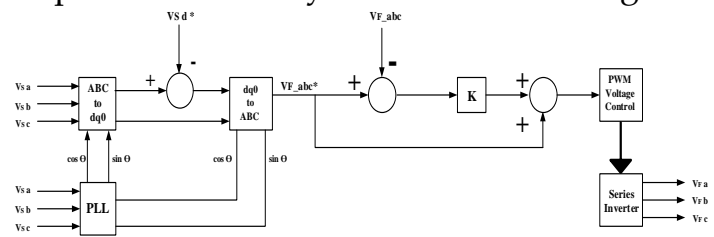

Fig.3: Control Scheme of the Series Compensato $r$ 
Using this method, harmonics, voltage sag, voltage swell, negative and zero sequence and imbalance of voltage can be extracted. This method can be used for sinusoidal, nonsinusoidal, symmetric and asymmetric voltages. In the theoretical method of synchronous reference frame, first, system's voltage with synchronous reference frame A-B-C is transformed into coordinate's d-q-0 according to the following equations.

$V_{s d q 0}=T_{a b c}^{d q 0} \quad V_{s a b c}$

$T_{a b c}^{d q}=\frac{2}{3}\left[\begin{array}{ccc}\cos \theta & \cos \left(\theta-\frac{2 \pi}{3}\right) & \cos \left(\theta+\frac{2 \pi}{3}\right) \\ \sin \theta & \sin \left(\theta-\frac{2 \pi}{3}\right) & \sin \left(\theta-\frac{2 \pi}{3}\right) \\ \frac{1}{2} & \frac{1}{2} & \frac{1}{2}\end{array}\right]$

In dq0 method, information comprising phase's depth and angle are extracted from (q) and voltage drop, beginning and ending time are extracted from (d). Namely, instead of high-pass and low-pass filters, desirable value of load's voltage phase is replaced in $d, q$ axes. Load's voltage should be totally sinusoidal with constant amplitude and frequency. Favorable prospective load's voltage is stated in Eq. 8:

$V_{l a b c}^{*}=T_{a b c}^{d q 0} V_{l a b c}^{*}=\left[\begin{array}{c}V_{m} \\ 0 \\ 0\end{array}\right]$

In Eq. 9, $\mathrm{V}$ is equal to

$$
V_{l a b c}^{*}=\left[\begin{array}{c}
V_{m} \cos (\omega t+\theta) \\
V_{m} \cos (\omega t+\theta-120) \\
V_{m} \cos (\omega t+\theta+120)
\end{array}\right]
$$

where $\mathrm{V}_{\text {sh }}$ is the desirable load's peak voltage is calculated.and $\Theta$ is the voltage's phase which is calculated by PLL. Reducing value of the desirable voltage, $V_{l d}^{*}$ is derived from $V_{s d}$ on d. in addition, the desirable phase voltage of the load on $\mathrm{q}$ is equal to zero. i.e. $V_{s q}$ demonstrates all disturbances on q. thus, series compensating reference is obtained:

$V_{f d q 0}^{*}=V_{l d q 0}^{*}-V_{s d q 0}$

In Pulse Width Modulation (PWM), these voltages are compared to a triangular waveform and required control pulses $g_{1}-g_{6}$ are generated to be applied to the series voltage converter.

\subsection{Parallel Compensator}

In this study, control solution for measuring the reduced current for unbalanced and nonlinear loads in active power filters is investigated. Current's harmonic distortion in three-phase electric power network is a serious problem due to the use of non-linear loads. Loads like diode or thyristor rectifiers and several power electronics-based equipments.

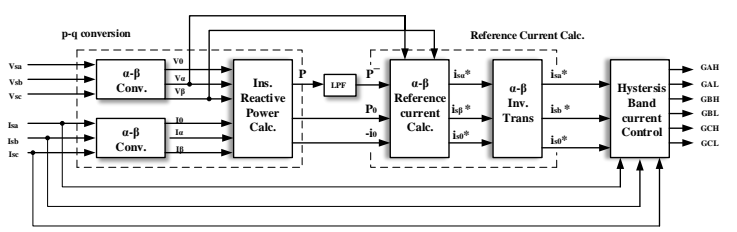

Fig. 4: Control Scheme of the Parallel Compensator

This control system as shown in Fig. 4 is the instantaneous reactive power theory (p-q) which is designed to control the parallel compensator in real time. In this theory, voltages and instantaneous three-phase current are transformed from coordinate A-B-C to coordinate $\alpha-\beta-0$ [24].

$\left[\begin{array}{l}V_{0} \\ V_{\alpha} \\ V_{\beta}\end{array}\right]=\sqrt{2 / 3}\left[\begin{array}{ccc}\frac{1}{\sqrt{2}} & \frac{1}{\sqrt{2}} & \frac{1}{\sqrt{2}} \\ 1 & -\frac{1}{2} & -\frac{1}{2} \\ 0 & \sqrt{3 / 2} & \sqrt{3 / 2}\end{array}\right]\left[\begin{array}{l}V_{s \alpha} \\ V_{s b} \\ V_{s c}\end{array}\right]$

$\left[\begin{array}{l}I_{0} \\ I_{\alpha} \\ I_{\beta}\end{array}\right]=\sqrt{2 / 3}\left[\begin{array}{ccc}\frac{1}{\sqrt{2}} & \frac{1}{\sqrt{2}} & \frac{1}{\sqrt{2}} \\ 1 & -\frac{1}{2} & -\frac{1}{2} \\ 0 & \sqrt{3 / 2} & \sqrt{3 / 2}\end{array}\right]\left[\begin{array}{c}I_{s \alpha} \\ I_{s b} \\ I_{s c}\end{array}\right]$

Real and imaginary components of the instantaneous power at load's side are calculated using the phase voltages and source currents shown in the equation below

Real and imaginary instantaneous powers including $\mathrm{AC}$ and $\mathrm{DC}$ components are given in the equation below:

$P=\tilde{P}+\bar{P}, q=\tilde{q}+\bar{q}$

DC components, $\mathrm{p}$ and $\mathrm{q}$ are derived from the positive components of the load's current $(\bar{q} s \bar{p})$, AC components $(\tilde{q} g \tilde{p})$ are derived 
from harmonic and negative components of the load's current.

$\left[\begin{array}{c}i_{S \alpha}^{*} \\ i_{S \beta}^{*}\end{array}\right]=\frac{1}{V_{\alpha}^{2}+V_{\beta}^{2}}\left[\begin{array}{cc}V_{\alpha} & -V_{\beta} \\ V_{\beta} & V_{\alpha}\end{array}\right]\left[\begin{array}{c}\bar{P} \\ 0\end{array}\right]$

$i_{s \beta}^{*} g i_{s \alpha}^{*}$ are the reference currents of the parallel converter in $\alpha-\beta-0$ coordinates. These currents are transformed into A-B-C three-phase system via the following equation.

$\left[\begin{array}{l}i_{s a}^{*} \\ i_{s b}^{*} \\ i_{s c}^{*}\end{array}\right]=\sqrt{2 / 3}\left[\begin{array}{ccc}1 / \sqrt{2} & 1 & 0 \\ 1 / \sqrt{2} & -\frac{1}{2} & \sqrt{3 / 2} \\ 1 / \sqrt{2} & -\frac{1}{2} & -\sqrt{3 / 2}\end{array}\right]\left[\begin{array}{l}i_{s 0}^{*} \\ i_{s a}^{*} \\ i_{s \beta}^{*}\end{array}\right]$

Reference currents in three-phase system $\left(i_{s a}^{*}, i_{s b}^{*}, i_{s c}^{*}\right)$ for compensating load's harmonic, are calculated. Switching signals adopted in this control algorithm are generated by comparing the reference currents to the desirable line current and using the control algorithm of the hysteresis loop current.

\section{Simulation Results}

According to Fig. 1, respective parameters for simulating the above system in SIMULINK are given in the table below.

Table. 1: Grid's Parameters

\begin{tabular}{|l|l|}
\hline Line voltage of the grid & $380 \mathrm{v}$ \\
\hline Grid's frequency & 50 \\
\hline Series inverter filter capacitance & $60 \mu \mathrm{f}$ \\
\hline Series inverter filter inductance & $3 \mathrm{mh}$ \\
\hline Parallel inverter filter inductance & $3 \mathrm{mh}$ \\
\hline Switching frequency for inverters & $10 \mathrm{kHz}$ \\
\hline Sensitive load's power & $20 \mathrm{kw}$ \\
\hline Non-linear load's capacitance & $.1 \mu \mathrm{f}$ \\
\hline Non-linear load's resistance & $60 \Omega$ \\
\hline DC bus voltage & $650 \mathrm{~V}$ \\
\hline
\end{tabular}

According to what has been previously stated, this control system must be able to resolve the source's voltage disturbances in addition to compensating undesirable effects of the non-linear loads. Thus, simulation results are given below:

4.1 Studying the synchronous presence of nonlinear loads and voltage sag

Fig. 5(a), (b), (c) show the grid's voltage, series converter's voltage and the load's voltage resulting from voltage sag within $0.15 \mathrm{~s}$ to $0.25 \mathrm{~s}$, respectively. Fig. 5(d), (e), (f) show the non-linear load's current, parallel converter's current and the grid's current respectively.

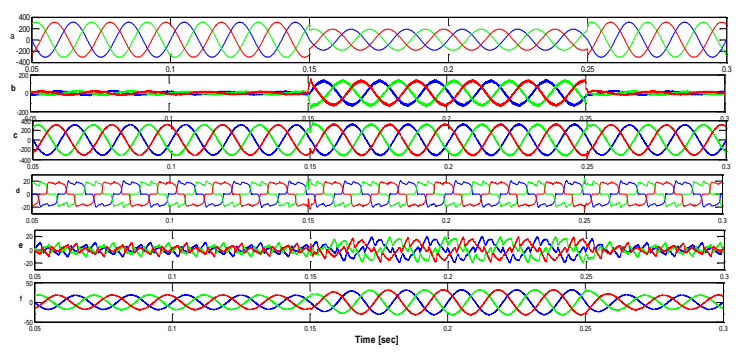

Fig. 5: Voltages and Currents of the Grid, Converters and Load resulting from voltage sag and non-linear load

Fig. 6 shows injected active and reactive power for compensating non-linear load effect and voltage sag.

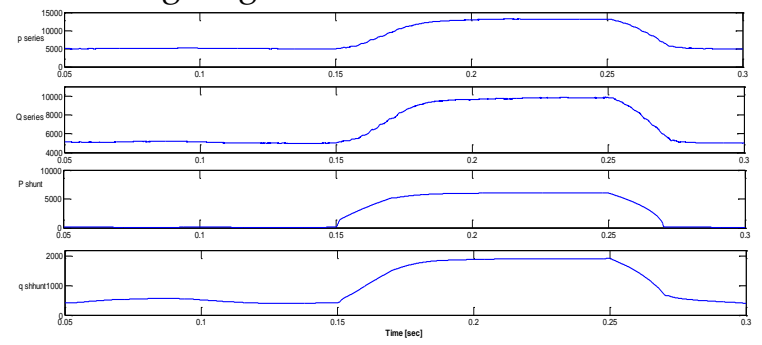

Fig. 6: injected active and reactive power for compensating non-linear load effect and voltage sag.

4.2 Studying the synchronous presence of nonlinear load and voltage swell

Fig. 7 (a), (b), (c) show the grid's voltage, series converter's voltage and load's voltage resulting from voltage swell within $0.2 \mathrm{~s}$ to $0.3 \mathrm{~s}$, respectively. Fig. 7 (d), (e), (f) show the nonlinear load's current, parallel converter's current and grid's current respectively.

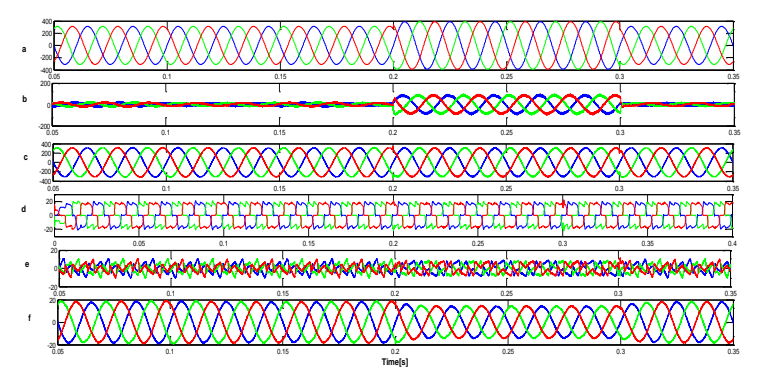

Fig.7: Voltages and Currents of the Grid, Converters and Load Resulting from Voltage Swell and Nonlinear Load

Fig. 8 shows the active and reactive powers injected to compensate the non-linear load effect and voltage swell. 


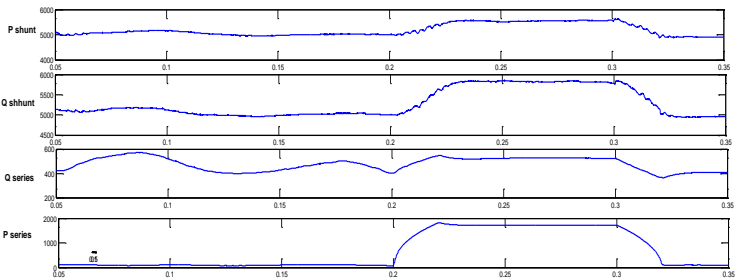

Fig. 8: Active and Reactive Powers Injected to Compensate the Non-linear Load Effect and Voltage Swell

4.3 Studying the Effect of Voltage Imbalance with 0.5 per-unit voltage swell, -45 phase gradient and negative sequence to grid's voltage in the presence of Sensitive load

Fig. 9 (a), (b), (c) show voltages of the grid, series converter and load affected by voltage imbalance, beginning at $0.15 \mathrm{~s}$ respectively. Fig. 9 (d), (e) illustrate the injected powers to compensate the imbalance effect.

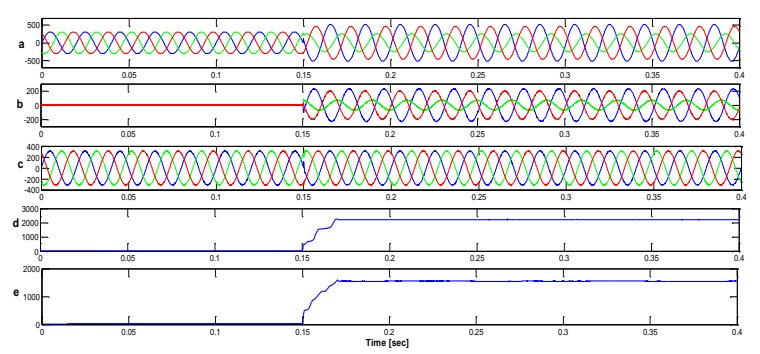

Fig. 9: Voltages of the grid, series compensator and load resulting from voltage imbalance

\subsection{Realization of $\cos \varphi=1$}

Finally, the figure below is illustrated to accomplish the last objective which is $\cos \varphi=1$

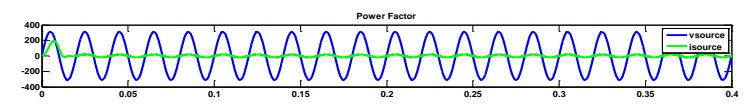

Fig. 10: Power Factor Unit

\section{Conclusion}

A power quality compensator in interface grids was reviewed to enhance the power quality in AC/DC hybrid microgirds. The compensator is implemented using parallel-series converters, such that both converters are optimally controlled to accomplish the task. By Using of this compensators, not only the voltage sags/swells were resolved, but also the destructive effect of the non-linear load was compensated. Calculations and simulations verify the positive effect of this compensator.

\section{References}

DOE. (2007) "The potential benefits of distributed generation and rate-related issues that may impede their expansion," DOE report.

B. Kroposki, R. Lasseter, T. Ise, S. Morozumi, S. Papathanassiou, and N. Hatziargyriou, (2008) "Making microgrids work," IEEE Power \& Energy Mag., vol. 6, no. 3, pp. 41-53.

R. H. Lasseter and P. Paigi, "Microgrid: A conceptual solution," (2004),inProc. IEEEPESC'04, pp. 4285-4290.

F. Katiraei, M. R. Iravani, A. L. Dimeas, and N. D. Hatziargyriou, (2008) “Microgrids management: control and operation aspects of microgrids,"IEEE Power Energy Mag., vol. 6, no. 3, pp. 54-65, May/Jun..

H. Nikkhajoei and R. H. Lasseter, (2009) "Distributed generation interface to the certs microgrid," IEEE Trans. Power Del., vol. 24, no. 3, pp.1598-1608,.

N. Eghtedarpour and E. Farjah, (2012) “Control strategy for distributed integrationof photovoltaic and energy storage systems in dc microgrids,"J. Renewable Energy, vol. 45, pp. 96-110.

L. Xu and D. Chen, (2011)“Control and operation of a DC microgrid withvariable generation and energy storage," IEEE Trans. Power Del., vol.26, no. 4, pp. 2513-2522..

M.H. Nehrir, C. Wang, K. Strunz, H. Aki, R. Ramakumar, J. Bing, Z. Miao, and Z. Salameh, (2011)"A Review of Hybrid Renewable/Alternative Energy Systems for Electric Power Generation: Configurations, Control, and Applications," IEEE Trans. Sustainable Energy, vol. 2, pp. 392-403.

X. Liu, P. Wang, and P. C.Loh, (2011) “A Hybrid AC / DC Microgrid and Its Coordination Control" IEEE Trans. Smart Grid, vol. 2, no. 2, pp. 278-286.

IEEE Standard for Interconnecting Distributed Resources with Electric Power Systems,( 2005) IEEE154. 
F. Blaabjerg, M. Liserre, and A.V. Timbus, (2006) "Overview of Control and Grid Synchronization for Distributed Power Generation Systems," IEEE Trans. Ind. Electron., vol. 53, pp. 1398-1409.

A. V. Jouanne, and B. Banerjee, "Assessment of voltage unbalance,"IEEE Trans. Power Deliv., vol. 16, no. 4, pp. 782-790, Oct. 2001.

D. Graovac, V. A. Katic', and A. Rufer, (2007) "Power quality problems compensation with universal power quality conditioning system,"IEEE Trans. Power Deliv., vol. 22, no. 2, pp. 968-976..

[15] B. Singh, K. Al-Haddad, and A. Chandra, “A review of active filters for power quality improvement," IEEE Trans. Ind. Electron., vol. 46,no. 5, pp. 960-971, Oct. 1999.

A. G. Cerrada , O. P. Ardila, V. F. Batlle, P. R. Sánchez, and P. G.González, "Application of a repetitive controller for a three-phase active power filter," IEEE Trans. Power Electron., vol. 22, no. 1, pp.237-246, Jan. 2007.

A. Chandra, B. Singh, B. N. Singh, and K. AlHaddad, (2000) "An improved control algorithm of shunt active filter for voltage regulation, harmonic elimination, power factor correction, and balancing of nonlinear loads," IEEE Trans. Power Electron., vol. 15,no. 3, pp. 495-507.

. Y. W. Li, D. M. Vilathgamuwa, and P. C. Loh, (2006) "A grid-interfacing power quality compensator for three-phase three-wire microgrid applications,"IEEE Trans. Power Electron., vol. 21, no. 4, pp. 1021-1031,Jul..

M. Xia and X.Li. (2013) "Design and Implementation of a High Quality Power Supply Scheme for Distributed Generation in a Micro-Grid" Energies, 6, 4924-4944; doi: 10.3390/en6094924.

R.; Ghosh, A.; Ledwich, G.; Zare, F. (2013) “Load sharing and power quality enhanced operation of a distributed micro-grid". IET Renew. Power Gener., 3, 109-119.

X. Li, P. Zhu, Y. Yang, and J. Chen, "A new control scheme for Series-parallel compensated UPS system," in Proc. IEEE Electric Machines and Drives. , 2003, pp. 1133-1136 vol.2.
Q.Sun "Hybrid Three-Phase/Single-Phase Microgrid Architecture with Power Management Capabilities" IEEE Trans. Power Electron., early access, 2015.

M.Fatihaa, M.Mohamadi, A.Nadiab “New hysteresis control band of an unified power quality conditioner" Electric Power Systems Research 81 (2011) 1743-1753

P. C. Loh, D. M. Vilathgamuwa, C. J. Gajanayake, L. T. Wong and C. P. Ang, "Z-Source CurrentType Inverters: Digital Modulation and Logic Implementation," IEEE Trans. on Power Electron., vol. 22, no.1, pp.169-177, 2007.

M. Kesler, E. Ozdemir, "Operation of Shunt Active Power Filter under Unbalanced and Distorted Load Conditions", the IEEE International Electric Machines and Drives Conference, IEMDC 2007, Antalya, Turkey, -, 608-613, (2007). 